\title{
Effects of Nozzle Geometry on Cavitation in Nozzles of Pressure Atomizers"
}

\author{
Akira SOU ${ }^{* *}$, Muhammad Ilham MAULANA ${ }^{* *}$, Kenji ISOZAKI**, \\ Shigeo HOSOKAWA ${ }^{* *}$ and Akio TOMIYAMA ${ }^{* *}$ \\ **Graduate School of Engineering, Kobe University, \\ 1-1, Rokkodai, Nadaku, Kobe, 657-8501, Japan \\ E-mail: sou@mech.kobe-u.ac.jp
}

\begin{abstract}
The effects of nozzle geometry on cavitation in the nozzle of pressure atomizers and the liquid jet are examined using various two-dimensional (2D) nozzles with different geometries. Then, whether or not the conventional cavitation numbers can be used to predict the formation of supercavitation, in which liquid jet atomization is enhanced, is examined. As a result, we confirm that (1) the thickness of the cavitation zone increases with the ratio $C_{u}$ of the cross-sectional area upstream of the nozzle to that of the nozzle, (2) the spray angle increases with $C_{u}$, (3) the formation of supercavitation can be predicted using the cavitation number $\sigma_{c}{ }^{\prime}$ in which the effects of the flow contraction and the frictional pressure drop are taken into account, and (4) the conventional cavitation numbers $\sigma, \sigma_{2}$ and $\sigma_{3}$ cannot predict the formation of supercavitation in nozzles with different geometries.
\end{abstract}

Key words: Cavitation, Nozzle, Cavitation Number, Injector, Atomization, Flow Contraction

\section{Introduction}

It has been pointed out that cavitation occurs in a nozzle of pressure atomizers, and influences atomization of a liquid jet discharged from the nozzle ${ }^{(1)}$. Hence, efforts have been made to visualize cavitation in nozzles ${ }^{(2)-(11)}$. The observations confirmed that liquid jet atomization is enhanced when cavitation is developed in a nozzle ${ }^{(2)-(6)}$, i.e., in the supercavitation regime ${ }^{(4),(6)}$. An indicator which can be utilized to predict the formation of supercavitation is, therefore, of great use in designing pressure atomizers.

In the previous study ${ }^{(12)}$ we confirmed that cavitation in a nozzle is strongly affected by the flow contraction in the nozzle. Since the contraction coefficient $C_{c}$ of a non-cavitating flow in a nozzle is affected by the ratio $C_{u}$ between the cross-sectional area upstream of the nozzle $A_{u}$ and that of the nozzle $A_{N}{ }^{(13)}, C_{u}$ may affect cavitation in a nozzle. The effects of the difference in $C_{u}$ on cavitation, however, have not been clarified yet.

Pressure atomizers with various nozzle geometries, e.g., hole nozzles and slit nozzles, have been developed. Efforts have been devoted to optimize nozzle geometries, since it is difficult to predict cavitation in the nozzles with different geometries. Various cavitation numbers have been proposed and used as an indicator of cavitation in nozzles ${ }^{(1)-(3),(6)-(11)}$. Although we have confirmed that one of the conventional cavitation numbers $\sigma^{(14)}$ can be used to predict development of cavitation in nozzles of fixed configurations ${ }^{(6)}$, it has been suggested that most of the cavitation numbers do not quantitatively predict development of cavitation in nozzles with different configurations. This can be because most of the

*Received 12 Mar., 2008 (No. 08-0170) [DOI: 10.1299/ffst.3.622] 
cavitation numbers do not take into account the effects of flow contraction. Hiroyasu et al. ${ }^{(2)}$ have proposed a cavitation number $\sigma_{c}$ which takes into account the pressure $P_{c}$ and the velocity $V_{c}$ in the vena contracta. Whether or not the cavitation number $\sigma_{c}$ can quantitatively predict the formation of supercavitation, however, has not been verified yet.

In this study cavitation in various two-dimensional (2D) nozzles with different upstream areas $A_{u}$ is visualized to investigate the effects of the difference in $C_{u}$ on cavitation and the liquid jet. Then, the experimental data on development of cavitation in the $2 \mathrm{D}$ nozzles and various cylindrical nozzles ${ }^{(5)}$ are used to examine whether or not the cavitation numbers can be utilized to predict the formation of supercavitation in nozzles with various geometries.

\section{Experimental setup and conditions}

Schematic of the experimental setup is shown in Fig. 1. Filtered tap water at room temperature was supplied from the plunger pump and discharged from the 2D nozzle into ambient air at atmospheric pressure (back pressure $P_{b}=0.101 \mathrm{MPa}$ ). The liquid flow rate was measured using flowmeters. The uncertainty in measured flow rate was less than $3.7 \%$. The injection pressure $P_{u}$ was measured at $100 \mathrm{~mm}$ upstream the nozzle using Bourdon pressure gauges. Images of cavitation and liquid jet were taken using a digital camera and a flash lamp (Nissin Electronic, MS-1000 \& LH-15M, duration $=4 \mu \mathrm{s}$ ). The concentration of oxygen dissolved in the water was measured using a dissolved oxygen probe (Hach company, HQ30d) and was about $9 \mathrm{mg} / \mathrm{L}$.

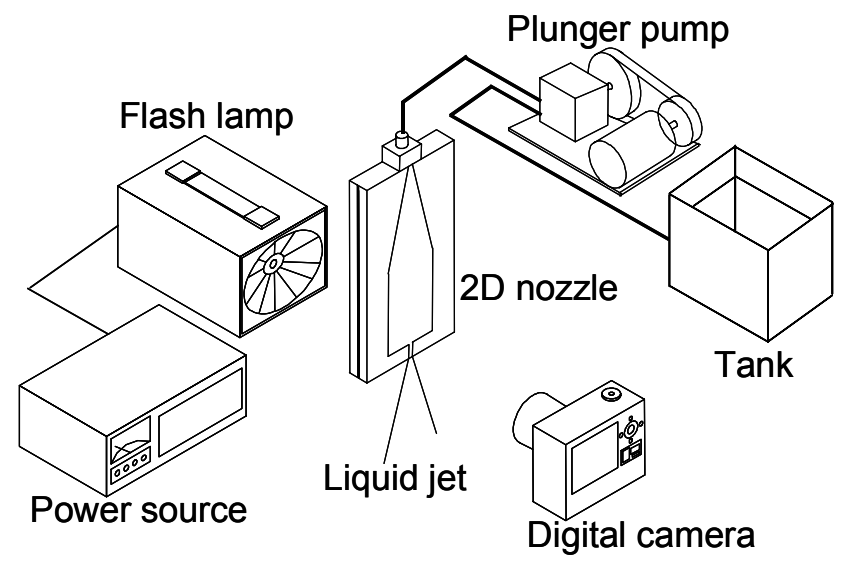

Fig. 1 Experimental setup

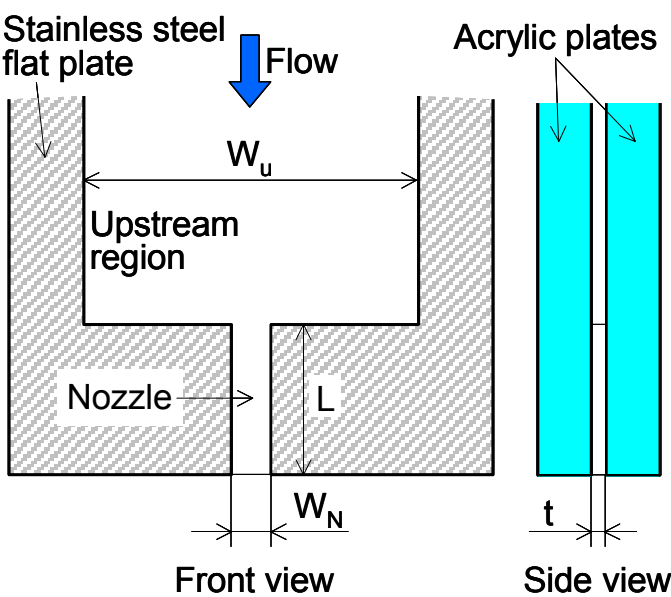

(a) Two-dimensional (2D) nozzle

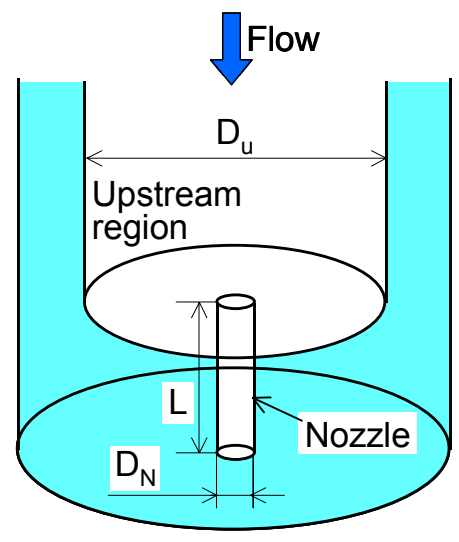

(b) Cylindrical nozzle

Fig. 2 Schematics of 2D and cylindrical nozzles 
Schematics of the 2D and cylindrical nozzles are shown in Figs. 2 (a) and (b), respectively. The dimensions of the $2 \mathrm{D}$ nozzles and those of the cylindrical nozzles ${ }^{(5)}$ are summarized in Tables 1 and 2, respectively. The 2D nozzles with various widths $W_{N}$, lengths $L$, thicknesses $t$ and upstream widths $W_{u}$ were used. Photos of cavitation in the cylindrical nozzles with various inner diameters $D_{N}$, lengths $L$ and upstream diameters $D_{u}$ were also used to examine the applicability of cavitation numbers to various nozzle geometries. The $C_{u}$ and $C_{c}$ in the tables are defined by

$$
\begin{gathered}
C_{u}=\frac{A_{u}}{A_{N}}=\frac{V_{N}}{V_{u}} \\
C_{c}=\frac{A_{c}}{A_{N}}=\frac{V_{N}}{V_{c}}
\end{gathered}
$$

where $A$ is the cross-sectional area, and $V$ the mean velocity in the cross section. The subscripts $u, N$ and $c$ denote the upstream region, the nozzle, and the vena contracta, respectively. How to evaluate $C_{c}$ will be described later.

Table 1 Dimensions of the 2D nozzles

\begin{tabular}{cccc}
\hline $\mathrm{W}_{\mathrm{N}} \times \mathrm{t}[\mathrm{mm}]$ & $\mathrm{C}_{\mathrm{u}}=\mathrm{A}_{\mathrm{u}} / \mathrm{A}_{\mathrm{N}}=\mathrm{W}_{\mathrm{u}} / \mathrm{W}_{\mathrm{N}}$ & $\mathrm{L} / \mathrm{W}_{\mathrm{N}}$ & $\mathrm{C}_{\mathrm{c}}=\mathrm{A}_{\mathrm{c}} / \mathrm{A}_{\mathrm{N}}$ \\
\hline $4.21 \times 0.98$ & 7.60 & 3.8 & 0.68 \\
$2.23 \times 0.47$ & 7.17 & 3.6 & 0.68 \\
$3.81 \times 0.95$ & 2.91 & 4.2 & 0.69 \\
$4.06 \times 0.95$ & 1.45 & 3.9 & 0.77 \\
\hline
\end{tabular}

Table 2 Dimensions of the cylindrical nozzles ${ }^{(5)}$

\begin{tabular}{cccc}
\hline $\mathrm{D}_{\mathrm{N}}[\mathrm{mm}]$ & $\mathrm{C}_{\mathrm{u}}=\mathrm{A}_{\mathrm{u}} / \mathrm{A}_{\mathrm{N}}=\left(\mathrm{D}_{\mathrm{u}} / \mathrm{D}_{\mathrm{N}}\right)^{2}$ & $\mathrm{~L} / \mathrm{D}_{\mathrm{N}}$ & $\mathrm{C}_{\mathrm{c}}=\mathrm{A}_{\mathrm{c}} / \mathrm{A}_{\mathrm{N}}$ \\
\hline 2.0 & 64 & 4 & 0.61 \\
1.0 & 100 & 4 & 0.61 \\
0.5 & 100 & 4 & 0.61 \\
1.0 & 4 & 4 & 0.625 \\
2.0 & 64 & 20 & 0.61 \\
0.5 & 100 & 20 & 0.61 \\
\hline
\end{tabular}

\section{Effects of nozzle geometry on cavitation and liquid jet}

Figures 3 (a) and (b) show cavitation and a liquid jet in the 2D nozzle of $4.21 \mathrm{~mm}$ in width $W_{N}$ and those in the half-scale nozzle, respectively. Figures 3 (c) and (d) are those in the $2 \mathrm{D}$ nozzles with smaller $C_{u}$. At $C_{u}=1.5$, hydraulic flip is not formed. Except for this case, an increase in $V_{N}$ (from left to right) results in the following transition ${ }^{(6)}$ : from no cavitation (dimensionless cavitation length $L^{*}=0$, where $L^{*}$ is the ratio of the streamwise length $L_{c a v}$ of the cavitation zone to the nozzle length $L$, i.e., $L^{*}=L_{c a v} / L$ ), developing cavitation (cavitation bubbles appear in the upstream half of the nozzle, $0<L^{*}<0.7$ ), supercavitation (cavitation films are formed in the upstream half and cavitation clouds are shed and collapse near the exit, $0.7<L^{*}<1$ ), to hydraulic flip (the reattachment of a separated boundary layer does not occur in the nozzle, $L^{*}=1$ ). Liquid jet atomization is enhanced in the supercavitation regime for all the nozzles. Images of cavitation in a cylindrical nozzle of $4 \mathrm{~mm}$ in diameter and a liquid jet are shown in Fig. 4 for comparison. Cavitation and liquid jet regimes show the same trends for $2 \mathrm{D}$ and cylindrical nozzles. Hence, once we can find an indicator for the formation of supercavitation, it is useful for a 


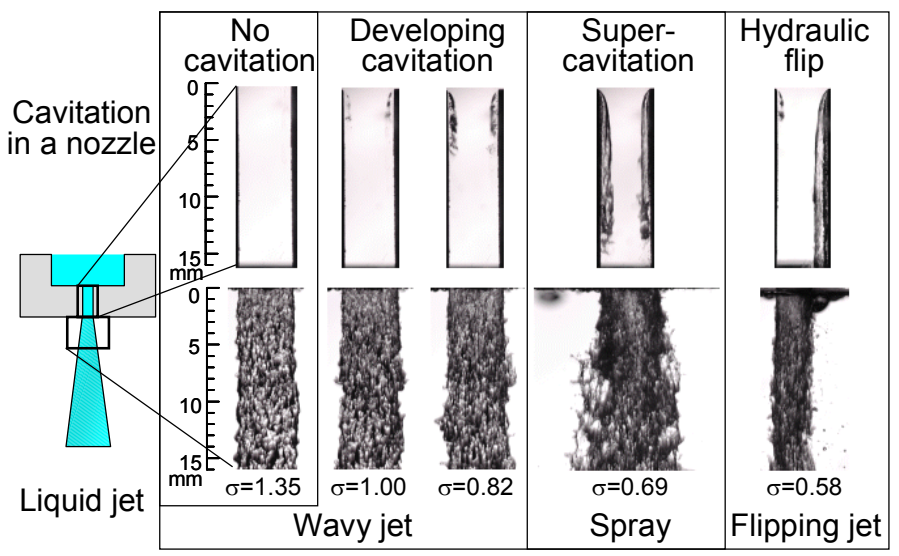

(a) $W_{N}=4.21 \mathrm{~mm}, C_{u} \simeq 7.6, L / W_{N} \simeq 4, W_{N} / t \simeq 4$

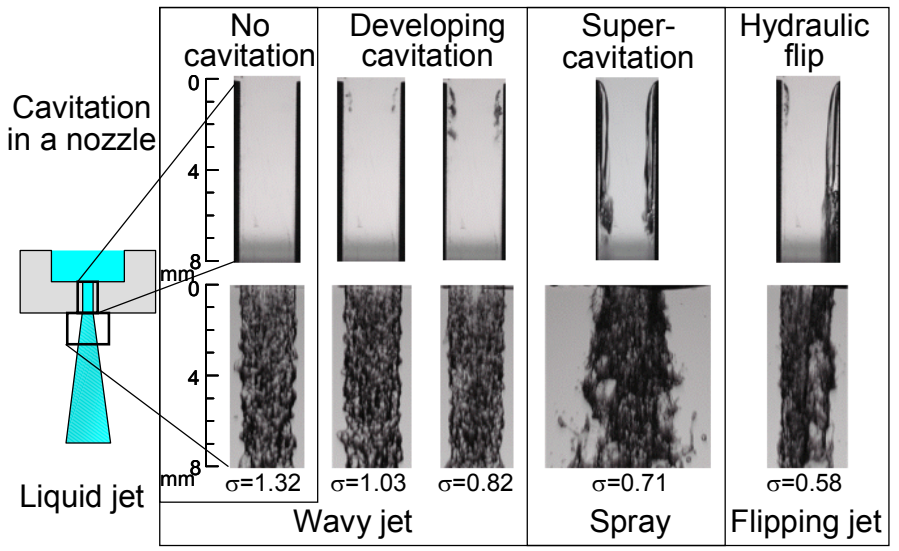

(b) $W_{N}=2.23 \mathrm{~mm}, C_{u} \simeq 7.2, L / W_{N} \simeq 4, W_{N} / t \simeq 4$

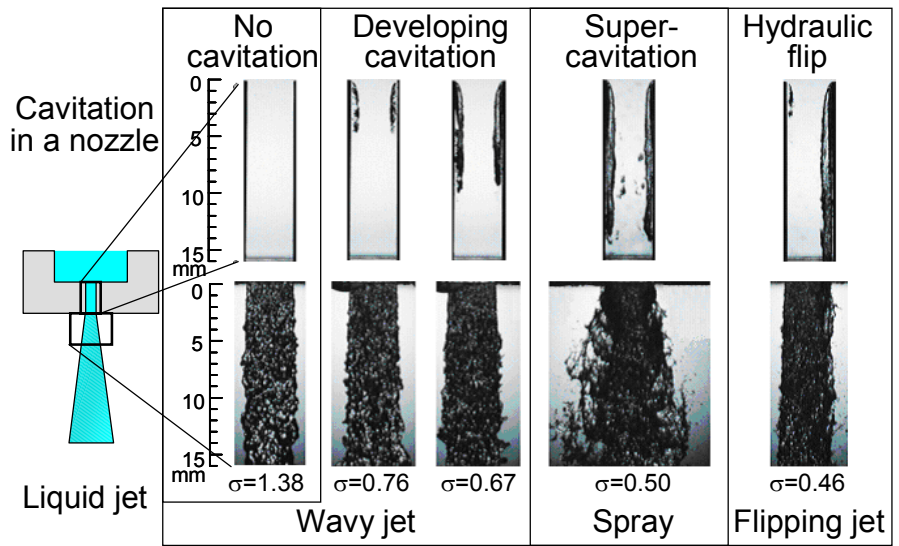

(c) $W_{N}=3.81 \mathrm{~mm}, C_{u} \simeq 2.9, L / W_{N} \simeq 4, W_{N} / t \simeq 4$

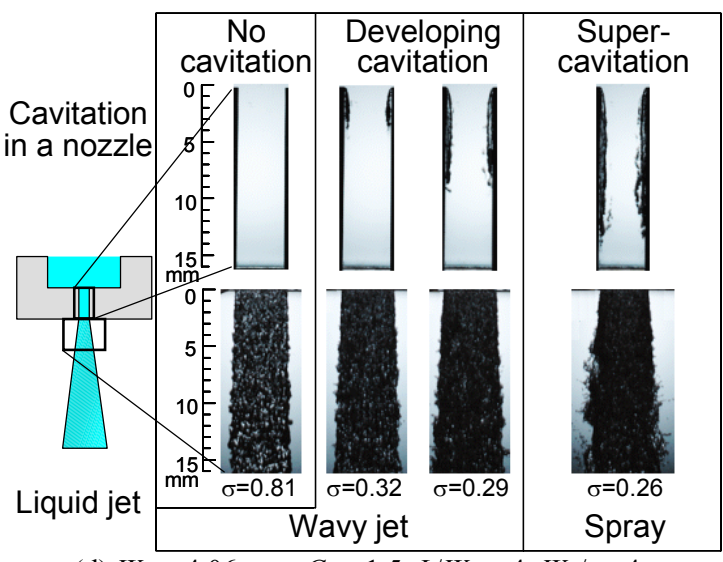

(d) $W_{N}=4.06 \mathrm{~mm}, C_{u} \simeq 1.5, L / W_{N} \simeq 4, W_{N} / t \simeq 4$

Fig. 3 Effects of nozzle size and shape on cavitation (2D nozzle) 


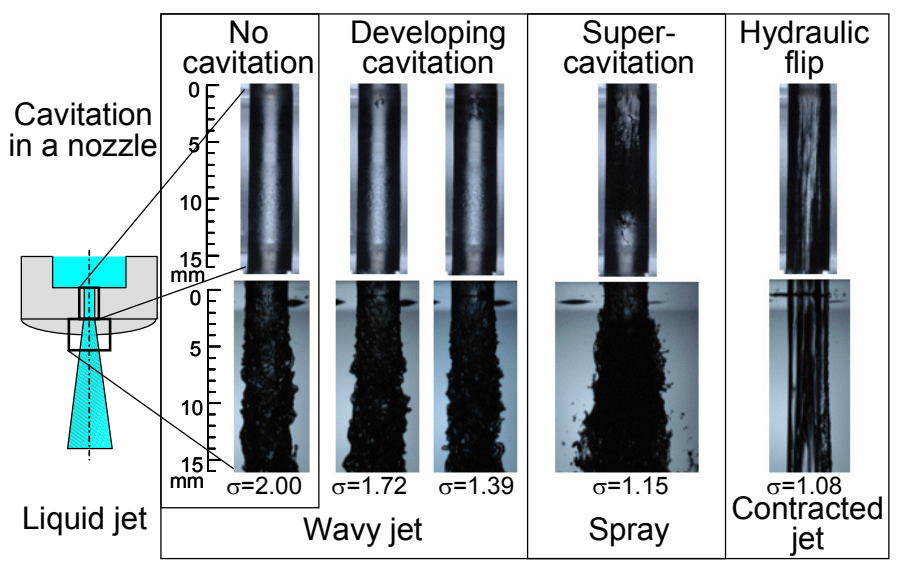

Fig. 4 Cavitation and liquid jet in a cylindrical nozzle $\left(D_{N}=4 \mathrm{~mm}, C_{u}=64, L / D_{N}=4\right)$

rational design of pressure atomizers. It should be noted that the spray angle $\theta^{(6)}$ in the supercavitation regime is smaller in the case of smaller $C_{u}$, i.e., the spray angle $\theta$ is $16^{\circ}$ for $C_{u}=7.6$ and 2.9, while $\theta=9^{\circ}$ for $C_{u}=1.5$.

The values of the conventional cavitation number $\sigma$ defined by Eq. (3) are shown in Figs. 3 and $4^{(6),(14)}$.

$$
\sigma=\frac{P_{b}-P_{v}}{\frac{1}{2} \rho V_{N}^{2}}
$$

where $P_{v}$ is the vapor saturation pressure and $\rho$ the liquid density. Cavitation is developed as $\sigma$ decreases for all the nozzles. As shown in Figs. 3 (a) and (b), supercavitation is formed at $\sigma \simeq 0.7$ in the nozzles of similar configurations. The agreement confirms that the formation of supercavitation in nozzles of similar configurations can be predicted using $\sigma$. On the other hand, as shown in Figs. 3 and 4, supercavitation is formed for smaller $\sigma$ when $C_{u}$ is smaller, e.g., supercavitation is formed at $\sigma=1.15$ for $C_{u}=64$, at $\sigma=0.69$ for $C_{u} \simeq 7.6$, and at $\sigma=0.26$ for $C_{u} \simeq 1.5$. The differences in $\sigma$ clearly demonstrate that we cannot use $\sigma$ to predict the formation of supercavitation in nozzles with different configurations.

Images of cavitation near the inlet of the 2D nozzles in supercavitation are shown in Fig. 5. The thickness $W_{c a v}$ of the cavitation zone increases with $C_{u}$. When $W_{c a v}$ is large, the velocity $V_{c}$ at vena contracta is large and the pressure $P_{c}$ at vena contracta is low. This is the reason why supercavitation is formed at smaller $\sigma$ in the case of smaller $C_{u}$. Hence, the flow contraction plays an important role in development of cavitation.

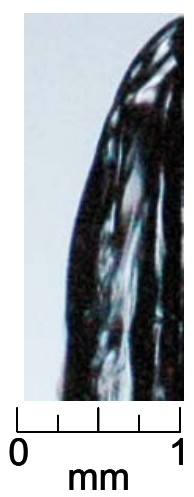

(a) $C_{u} \sim 7.6$

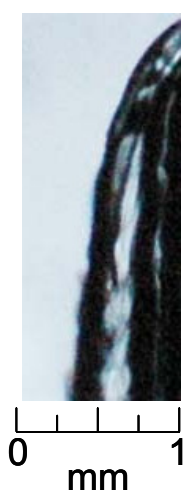

(b) $C_{u} \sim 2.9$

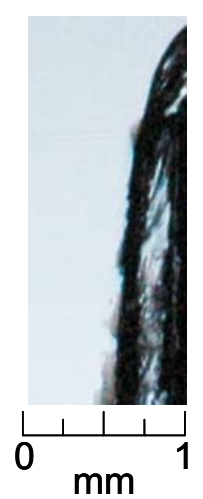

(c) $C_{u} \simeq 1.5$

Fig. 5 Effect of $C_{u}$ on cavitation thickness ( $W_{N} \simeq 4 \mathrm{~mm}, L=16 \mathrm{~mm}$ ) 


\section{Various cavitation numbers}

In addition to the cavitation number $\sigma$ defined by Eq. (3), various cavitation numbers have been proposed and used as an indicator for development of cavitation in nozzles. Bergwerk ${ }^{(1)}$, Soteriou et al. ${ }^{(3)}$ and many other researchers ${ }^{(7)-(9)}$ have used the cavitation number $\sigma_{2}$ :

$$
\sigma_{2}=\frac{P_{u}-P_{b}}{P_{b}-P_{v}}
$$

Nurick ${ }^{(10)}$ and Payri et al. ${ }^{(11)}$ used the cavitation number $\sigma_{3}$ defined by

$$
\sigma_{3}=\frac{P_{u}-P_{v}}{P_{u}-P_{b}}
$$

Note that the cavitation numbers $\sigma, \sigma_{2}$ and $\sigma_{3}$ do not take into account the effects of flow contraction, and they have been used not only for nozzles but for long orifices ${ }^{(15),(16)}$.

Figure 6 shows the time-averaged liquid velocity distribution obtained by using a Laser Doppler Velocimetry (LDV) system in a cavitating nozzle of $4 \mathrm{~mm}$ in width ${ }^{(12)}$. Flow contraction is formed at the inlet, and the velocity distribution near the exit is uniform. Based on the velocity distribution, we can obtain the pressure distribution along the axis of a nozzle shown in Fig. 7. Cavitation inception takes place in the separated boundary layer where the static pressure takes the lowest value.

Hiroyasu et al. ${ }^{(2)}$ proposed the cavitation number $\sigma_{c}$, which is defined as

$$
\sigma_{c}=\frac{P_{c}-P_{v}}{\frac{1}{2} \rho V_{c}^{2}}
$$

The definition of $\sigma_{c}$ is similar to that of $\sigma$ defined by Eq. (3). The pressure $P_{c}$ and the velocity $V_{c}$ at the vena contracta are used in $\sigma_{c}$. To evaluate $P_{c}$ in Eq. (6), they used the Bernoulli's equation:

$$
P_{c}+\frac{1}{2} \rho V_{c}^{2}=P_{b}+\frac{1}{2} \rho V_{N}^{2}+\frac{\lambda\left(L-L_{c a v}\right)}{D_{H}} \frac{1}{2} \rho V_{N}^{2}
$$

where $\lambda$ is the friction factor, and $D_{H}$ the hydraulic equivalent diameter of a nozzle. Substituting Eqs. (2) and (7) into Eq. (6) yields

$$
\sigma_{c}=C_{c}^{2}\left[\frac{P_{b}-P_{v}}{\frac{1}{2} \rho V_{N}^{2}}+\frac{\lambda\left(L-L_{c a v}\right)}{D_{H}}+1\right]-1
$$

They assumed that (i) $C_{c}=0.6$ and (ii) $\lambda\left(L-L_{c a v}\right) / D_{H}=0$, and carried out a validation test of $\sigma_{c}$ defined by Eq. (9).

$$
\sigma_{c}=0.36\left[\frac{P_{b}-P_{v}}{\frac{1}{2} \rho V_{N}^{2}}+1\right]-1
$$


Although they found that cavitation is likely to be developed for low $\sigma_{c}$, they failed in a quantitative prediction of cavitation regime using $\sigma_{c}$ given by Eq. (9). They suggested that quantitative verifications of the validity of $\sigma_{c}$ are needed. No quantitative verification, however, has been carried out yet.

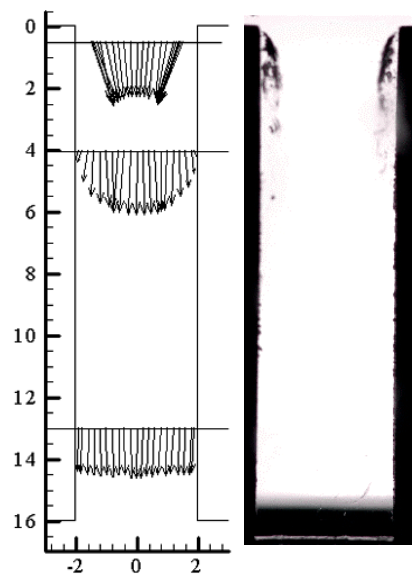

Fig. 6 Time-averaged liquid velocity distribution in the $2 \mathrm{D}$ nozzle $\left(W_{N}=4 \mathrm{~mm}\right)^{(12)}$

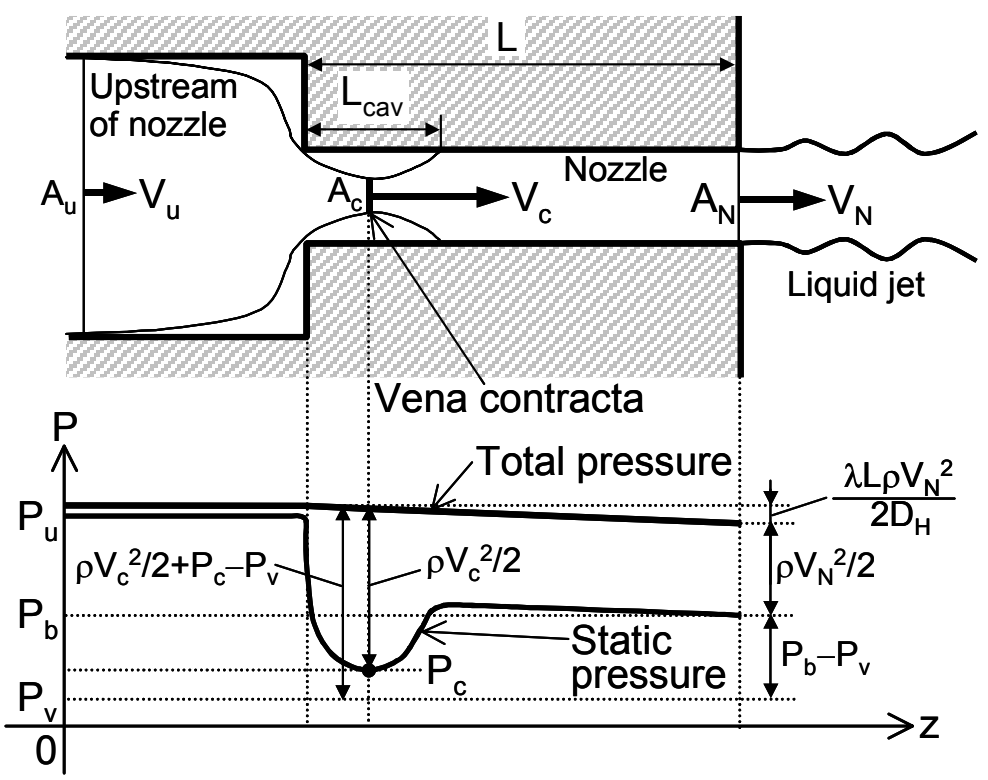

Fig. 7 Pressure distribution in a cavitating nozzle

\section{Applicability of the cavitation numbers}

Whether or not the cavitation numbers $\sigma, \sigma_{2}, \sigma_{3}$ and $\sigma_{c}$ can predict the formation of supercavitation in nozzles of various geometries is tested. The dimensionless cavitation length $L^{*}$ is used to represent the formation of supercavitation, i.e., $0.7<L^{*}<1$.

Considering the applicability of $\sigma_{c}$ to long nozzles in which the frictional pressure drop is not negligible, we evaluate $\sigma_{c}$ by

$$
\sigma_{c}=C_{c}^{2}\left[\frac{P_{b}-P_{v}}{\frac{1}{2} \rho V_{N}^{2}}+\frac{\lambda L}{D_{H}}+1\right]-1
$$

The friction factor $\lambda$ in Eq. (10) is calculated using 


$$
\begin{gathered}
\lambda=\beta \frac{0.3164}{R e^{0.25}} \\
R e=\frac{D_{H} V_{N}}{v_{L}}
\end{gathered}
$$

where $\beta$ is given by ${ }^{(13)}$

$$
\beta= \begin{cases}1.00 & \text { for cylindrical nozzles } \\ 1.15 & \text { for } 2 \mathrm{D} \text { nozzles of } W_{N} / t \cong 4\end{cases}
$$

The $C_{c}$ for a cylindrical nozzle can be given as a function of $C_{u}{ }^{(13)}$. Since there are no appropriate correlations of $C_{c}$ for $2 \mathrm{D}$ nozzles, $C_{c}$ for the $2 \mathrm{D}$ nozzles is given using the measured $W_{\text {cav }}$ :

$$
C_{c}= \begin{cases}0.61 & \text { for cylindrical nozzles of } C_{u} \geq 10 \\ 0.625 & \text { for cylindrical nozzles of } C_{u}=4 \\ 1-\frac{2 W_{c a v}}{W_{N}} & \text { for 2D nozzles }\end{cases}
$$

where $W_{c a v}$ is the cavitation thickness measured at $0.1 \mathrm{~L}$ downstream of the nozzle inlet, at which the cavitation thickness and the time-averaged streamwise velocity reach constant values in the streamwise direction. Note that we have verified the validity of Eq. (14) for 2D nozzle based on liquid velocity distribution measured by using $\mathrm{LDV}^{(12)}$.

Figure 8 shows the relations between $L^{*}$ and the cavitation numbers, $\sigma, \sigma_{2}, \sigma_{3}$ and $\sigma_{c}$. As shown in Fig. 8 (a), supercavitation $\left(0.7<L^{*}<1\right)$ takes place for larger $\sigma$ in the cylindrical short nozzles (the length-to-diameter ratio $L / D_{N}=4$ ) than in the 2D nozzles. Since $C_{c}$ of the cylindrical short nozzle is smaller than that of the $2 \mathrm{D}$ nozzle, the discrepancy in $\sigma$ indicates that the degree of flow contraction $\left(C_{c}\right)$ has to be taken into account to predict the formation of supercavitation in various nozzles. Supercavitation is formed for larger $\sigma$ in the cylindrical short nozzles $\left(L / D_{N}=4\right)$ than in the long nozzles $\left(L / D_{N}=20\right)$. The difference indicates the importance of the frictional pressure drop. As shown in Figs. 8 (b) and (c), the similar discrepancies among the nozzles with different geometries can be seen for $\sigma_{2}$ and $\sigma_{3}$. (Note that $\sigma_{2}$ shows the opposite trends due to its definition.) These discrepancies clearly indicate that $\sigma, \sigma_{2}$ and $\sigma_{3}$, which do not take into account the effects of the flow contraction and frictional pressure drop, cannot predict the formation of supercavitation for nozzles of different geometries.

To the contrary, the relation between $L^{*}$ and $\sigma_{c}$ does not strongly depend on the nozzle geometry, that is, supercavitation is formed at $\sigma_{c}=-0.13 \pm 0.05$ for all the nozzles. Thus, the formation of supercavitation in nozzles with different geometries can be predicted using $\sigma_{c}$ defined by Eq. (10).

The failure in the prediction of the formation of supercavitation using $\sigma_{c}$ defined by Eq. (9) by Hiroyasu et al. ${ }^{(2)}$ may be due to (i) the disregard of the frictional pressure drop, (ii) error in $C_{c}$ due to dull edges of the nozzle inlet and (iii) measurement errors in $V_{N}$.

It should be noted that actual pressure at the vena contracta $P_{c}$ is always higher than $P_{v}$, since hydraulic flip is formed before $P_{c}$ becomes lower than $P_{v}$. In hydraulic flip, the actual pressure distribution differs from the pressure distribution shown in Fig. 7 and $P_{c}$ becomes $P_{b}$. However, $\sigma_{c}$ calculated by Eq. (10) is found to be useful for predicting supercavitation. 


\section{Science and Technology}

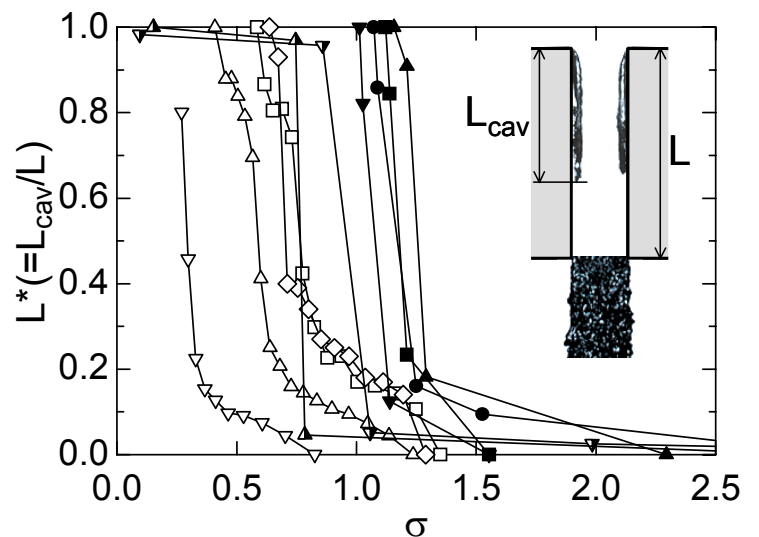

(a) $L^{*}$ vs. $\sigma$ given by Eq. (3)

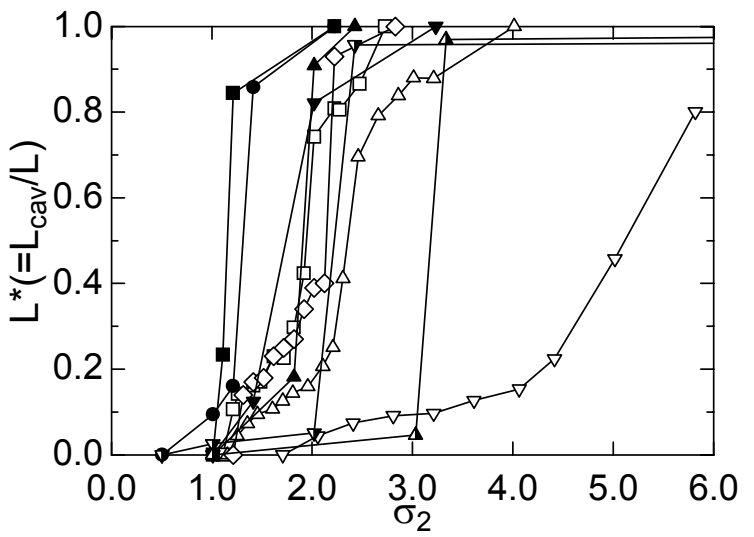

2D Nozzle

$\rightarrow-\mathrm{W}_{\mathrm{N}}=4.2 \mathrm{~mm}, \mathrm{C}_{\mathrm{u}}=7.6, \mathrm{~L} / \mathrm{W}_{\mathrm{N}}=3.8$ $\checkmark \mathrm{W}_{\mathrm{N}}=2.2 \mathrm{~mm}, \mathrm{C}_{\mathrm{u}}=7.2, \mathrm{~L} / \mathrm{W}_{\mathrm{N}}=3.6$ $-\triangle-\mathrm{W}_{\mathrm{N}}=3.8 \mathrm{~mm}, \mathrm{C}_{\mathrm{U}}=2.9, \mathrm{~L} / \mathrm{W}_{\mathrm{N}}=4.2$ $\rightarrow-\mathrm{W}_{\mathrm{N}}=4.1 \mathrm{~mm}, \mathrm{C}_{\mathrm{u}}=1.5, \mathrm{~L} / \mathrm{W}_{\mathrm{N}}=3.9$

\section{Cylindrical Nozzle}

- $D_{N}=2.0 \mathrm{~mm}, C_{N}=64, L / D_{N}=4$

$-D_{N}=1.0 \mathrm{~mm}, C_{u}=100, L / D_{N}=4$ $\therefore-D_{N}=0.5 \mathrm{~mm}, C_{u}=100, L / D_{N}=4$ $\rightarrow D_{N}=1.0 \mathrm{~mm}, C_{u}=4, \quad L / D_{N}=4$ $\longrightarrow D_{\mathrm{N}}=2.0 \mathrm{~mm}, \mathrm{C}_{\mathrm{u}}=64, \mathrm{~L} / \mathrm{D}_{\mathrm{N}}=20$ $\leadsto-D_{N}=0.5 \mathrm{~mm}, C_{\mathrm{u}}=100, L / D_{N}=20$

(b) $L^{*}$ vs. $\sigma_{2}$ given by Eq. (4)

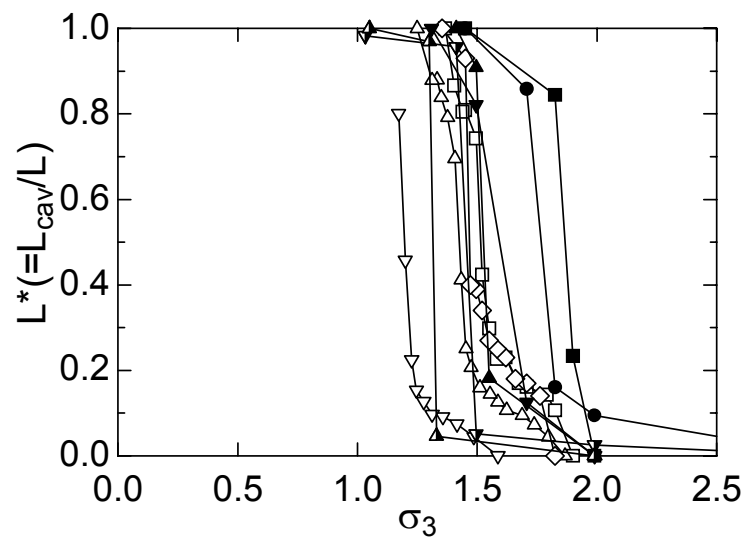

2D Nozzle

$\rightarrow-\mathrm{W}_{\mathrm{N}}=4.2 \mathrm{~mm}, \mathrm{C}_{\mathrm{u}}=7.6, \mathrm{~L} / \mathrm{W}_{\mathrm{N}}=3.8$ $\checkmark-W_{N}=2.2 \mathrm{~mm}, \mathrm{C}_{\mathrm{u}}=7.2, \mathrm{~L} / \mathrm{W}_{\mathrm{N}}=3.6$ $\triangle-\mathrm{W}_{\mathrm{N}}=3.8 \mathrm{~mm}, \mathrm{C}_{\mathrm{u}}=2.9, \mathrm{~L} / \mathrm{W}_{\mathrm{N}}=4.2$ $\rightarrow-\mathrm{W}_{\mathrm{N}}=4.1 \mathrm{~mm}, \mathrm{C}_{\mathrm{u}}=1.5, \mathrm{~L} / \mathrm{W}_{\mathrm{N}}=3.9$

Cylindrical Nozzle

$-D_{N}=2.0 \mathrm{~mm}, C_{u}=64, L / D_{N}=4$ $\rightarrow D_{N}=1.0 \mathrm{~mm}, C_{u}=100, L / D_{N}=4$ $\triangle D_{N}=0.5 \mathrm{~mm}, C_{4}=100, L / D_{N}=4$ $\rightarrow D_{N}=1.0 \mathrm{~mm}, C_{u}=4, \quad L / D_{N}=4$ $\rightarrow-D_{N}=2.0 \mathrm{~mm}, C_{\mathrm{u}}=64, L / D_{N}=20$ $\neg-D_{N}=0.5 \mathrm{~mm}, C_{u}=100, L / D_{N}=20$

(c) $L^{*}$ vs. $\sigma_{3}$ given by Eq. (5)

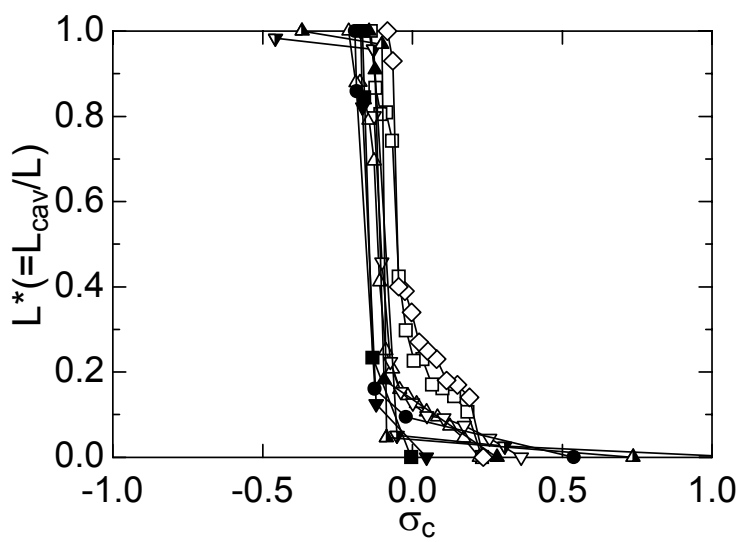

2D Nozzle

$\rightarrow \square-\mathrm{W}_{\mathrm{N}}=4.2 \mathrm{~mm}, \mathrm{C}_{\mathrm{u}}=7.6, \mathrm{~L} / \mathrm{W}_{\mathrm{N}}=3.8$ $\checkmark-\mathrm{W}_{\mathrm{N}}=2.2 \mathrm{~mm}, \mathrm{C}_{\mathrm{u}}=7.2, \mathrm{~L} / \mathrm{W}_{\mathrm{N}}=3.6$ $\triangle-\mathrm{W}_{\mathrm{N}}=3.8 \mathrm{~mm}, \mathrm{C}_{\mathrm{u}}=2.9, \mathrm{~L} / \mathrm{W}_{\mathrm{N}}=4.2$ $\rightarrow-\mathrm{W}_{\mathrm{N}}=4.1 \mathrm{~mm}, \mathrm{C}_{\mathrm{u}}=1.5, \mathrm{~L} / \mathrm{W}_{\mathrm{N}}=3.9$

Cylindrical Nozzle

- $\mathrm{D}_{\mathrm{N}}=2.0 \mathrm{~mm}, \mathrm{C}_{\mathrm{u}}=64, \mathrm{~L} / \mathrm{D}_{\mathrm{N}}=4$ $\rightarrow-D_{N}=1.0 \mathrm{~mm}, C_{u}=100, L / D_{N}=4$ $\neg \mathrm{D}_{\mathrm{N}}=0.5 \mathrm{~mm}, \mathrm{C}_{\mathrm{u}}=100, \mathrm{~L} / \mathrm{D}_{\mathrm{N}}=4$ $\rightarrow D_{N}=1.0 \mathrm{~mm}, C_{4}=4, L / D_{N}=4$ $\rightarrow-D_{N}=2.0 \mathrm{~mm}, C_{u}=64, L / D_{N}=20$ $\neg-D_{N}=0.5 \mathrm{~mm}, C_{u}=100, L / D_{N}=20$

(d) $L^{*}$ vs. $\sigma_{c}$ given by Eq. $(10)$

Fig. 8 Relation between $L^{*}\left(=L_{c a v} / L\right)$ and the cavitation numbers 
Note that both $\sigma_{c}$ given by Eq. (8) and that by Eq. (10) are found to give good predictions. Since Eq. (10) does not include $L_{c a v}$ in its RHS, we can calculate its value more easily.

It should be also noted that $C_{c}$ of the 2D nozzle was evaluated using Eq. (14), and the values of $C_{c}$ of non-cavitating flows in cylindrical nozzles were used for those of the cavitating cylindrical nozzle. Hence, the agreement between the $2 \mathrm{D}$ and cylindrical nozzles implies that the thickness of the separated boundary layer can be regarded as that of cavitation zone.

Based on the concept of the traditional cavitation number ${ }^{(14)}$, the cavitation number $\sigma_{c}{ }^{\prime}$ can be defined:

$$
\sigma_{c}{ }^{\prime}=\frac{\frac{1}{2} \rho V_{c}^{2}+P_{c}-P_{v}}{\frac{1}{2} \rho V_{c}^{2}}
$$

Since $\sigma_{c}{ }^{\prime}=\sigma_{c}+1, \sigma_{c}{ }^{\prime}$ can be expressed as

$$
\sigma_{c}{ }^{\prime}=C_{c}^{2}\left[\frac{P_{b}-P_{v}}{\frac{1}{2} \rho V_{N}^{2}}+\frac{\lambda L}{D_{H}}+1\right]
$$

Supercavitation is to be formed for $\sigma_{c}{ }^{\prime} \simeq 0.87 \pm 0.05$, and cavitation inception takes place for $\sigma_{c}{ }^{\prime} \simeq 1.05 \pm 0.15$. Note that cavitation inception occurs when $\sigma_{c}{ }^{\prime}$ is close to unity.

\section{Conclusions}

The effects of nozzle geometry on cavitation in the nozzle of pressure atomizers are examined using two-dimensional (2D) nozzles of various geometries. Then, whether or not the conventional cavitation numbers can be utilized to predict the formation of supercavitation, at which liquid jet atomization is promoted, in various nozzles with different geometries is examined using the experimental data on development of cavitation in the $2 \mathrm{D}$ and cylindrical nozzles. As a result, the following conclusions are obtained:

(1) The thickness $W_{c a v}$ of the cavitation zone in the supercavitation regime increases with the ratio $C_{u}$ of the cross-sectional area upstream of the nozzle to that of the nozzle.

(2) In the supercavitation regime, the spray angle $\theta$ increases with $C_{u}$.

(3) We can predict the formation of supercavitation in nozzles with various geometries using the cavitation number $\sigma_{c}^{\prime}$, in which the effects of the flow contraction and frictional pressure drop are take into account.

(4) The other conventional cavitation numbers $\sigma, \sigma_{2}$ and $\sigma_{3}$ are not appropriate for predicting the formation of supercavitation in nozzles with various geometries.

\section{Acknowledgements}

The authors would like to express their thanks to Mr. Daisuke Goshima of Kobe University. This study was supported by a Grant-in-Aid for Scientific Research (No. 18560170) from the Japan Society for the Promotion Science (JSPS).

\section{References}

(1) Bergwerk, W., Flow Pattern in Diesel Nozzle Spray Holes, Proceedings of the Institute of 
Mechanical Engineers, Vol. 173, No. 25 (1959), pp. 655-660.

(2) Hiroyasu, H., Arai, M. and Shimizu, M., Break-up Length of a Liquid Jet and Internal Flow in a Nozzle, Proceedings of International Conference on Liquid Atomization and Spray Systems 91 (ICLASS 91) (1991), pp. 275-282.

(3) Soteriou, C., Andrews, R. and Smith, R., Direct Injection Diesel Sprays and The Effect Cavitation and Hydraulic Flip on Atomization, SAE Paper (1995), Paper No. 950080.

(4) Chaves, H., Knapp, M., Kubitzek, A., Obermeier, F. and Schneider, T., Experimental Study of Cavitation in the Nozzle Hole of Diesel Injectors Using Transparent Nozzles, SAE Paper (1995), Paper No. 950290, pp. 645-657.

(5) Tamaki, N., Flow in a Nozzle and Mechanism on Atomization of a Liquid Jet (in Japanese), Dr. Thesis, Hiroshima University, (1997). See also Tamaki, N., Shimizu, M., Nishida, K. and Hiroyasu, H., Effects of Cavitation and Internal Flow on Atomization of a Liquid Jet, Atomization and Sprays, Vol. 8 (1998), pp. 179-197.

(6) Sou, A., Hosokawa, S. and Tomiyama, A., Effects of Cavitation in a Nozzle on Liquid Jet Atomization, International Journal of Heat and Mass Transfer, Vol. 50, Iss. 17-18, (2007), pp. 3575-3582.

(7) Iida, H., Matsumura, E., Tanaka, K., Senda, J., Fujimoto, H. and Maly, R. R., Effects of Internal Flow in a Simulated Diesel Injection Nozzle on Spray Atomization, CD-ROM of 8th International Conference on Liquid Atomization and Spray Systems (ICLASS 2000) (2000), pp. 179-197.

(8) Baz, I., Champoussin, J.-C., Lance, M. and Marie, J.-L., Investigation of The Cavitation in High Pressure Diesel Injection Nozzles, CD-ROM of ASME FEDSM '02 (2002), FEDSM2002-31015.

(9) Miranda, R,. Chaves, M., Martin, U. and Obermeier, F., Cavitation In a Tranparaent Real Size VCO Injection Nozzle, CD-ROM of International Conference on Liquid Atomization and Spray Systems 2003 (ICLASS 2003) (2003), CD-ROM.

(10) Nurick, W. H., Orifice Cavitation and Its Effect on Spray Mixing, Journal of Fluid Engineering, Transactions of ASME (1976), pp. 681-687.

(11) Payri, F., Bermudez, V., Payri, R. and Salvador, F. J., The Influence of Cavitation in on the Internal Flow and the Spray Characteristics in Diesel Injection Nozzles, Fuel, Vol. 83, (2004), pp. 419-431.

(12) Sou, A., Tomiyama, A., Hosokawa, S., Nigorikawa, S. and Maeda, T., Cavitation in a Two-Dimensional Nozzle and Liquid Jet Atomization (LDV Measurement of Liquid Velocity in a Nozzle), JSME International Journal, Series B, Vol. 49, No. 4, (2006) pp. 1253-1259.

(13) JSME, e.d., JSME Data Book, Hydraulic Losses in Pipe and Ducts, (2004) Maruzen.

(14) Knapp, R. T., Daily, J. W. and Hammitt, F. G., Cavitation, McGraw-Hill, (1970).

(15) Kamiyama, S. and Yamasaki, T., Critical Condition of Cavitation Occurrence in Various Liquids, Journal of Fluid Engineering, Transactions of ASME, Vol. 108, (1986) pp. 428-432.

(16) Yan, Y. and Thorpe, R. B., Flow Regime Transitions due to Cavitation in the Flow through an Orifice, International Journal of Multiphase Flow, Vol. 16, Iss. 6, (1990) pp. 1023-1045. 